\title{
Projeto de extensão como ferramenta para promover a saúde de gestantes adolescentes em situação de vulnerabilidade
}

\author{
Franciane Silva Luiz, Mara Rúbia Maciel Cardoso do Prado, Silas Teixeira de Souza, Fernanda \\ Barbieri Boro
}

\begin{abstract}
Resumo
A gravidez na adolescência é um problema de saúde pública e um desafio para os profissionais de saúde, visto que tal fenômeno impacta negativamente na integralidade da saúde materno-fetal. O mesmo ocorre no Brasil, onde existe ainda um alto índice de gravidez neste ciclo de vida. Sabe-se que independente da maternidade, esta é uma fase frágil devido às mudanças biopsicossociais sofridas e assim, a gravidez na adolescência potencializa um processo já conflituoso e complexo. Nesta perspectiva, a maternidade precoce necessita de um apoio social formado pela família, comunidade, escola e serviços de saúde, em especial as consultas de pré-natal são essenciais para a superação da vulnerabilidade e os respectivos fatores de risco da gestação precoce na adolescência. É neste contexto que se retrata a importância de projetos de extensão que viabilizem o cuidado integral a esse público alvo que se encontra em situação de vulnerabilidade. Demonstrar a importância do projeto de extensão ao viabilizar um cuidado integral à adolescentes gestantes em situação de vulnerabilidade no município de Viçosa-MG. O projeto ocorrerá em três etapas que irão de encontro ao trimestre de gestação em que a participante se encontra, sendo para tanto realizadas visitas domiciliares (VDs) em cada etapa. $\mathrm{Na} 1^{\text {a }}$ etapa será trabalhado questões que abarquem a importância da realização do pré-natal e questões que envolvam o parto e o pós-parto, sendo utilizado como auxílio o álbum seriado "Família brasileira fortalecida: pré-natal, parto e pós-parto". Durante a $2^{\mathrm{a}}$ etapa será abordado questões referentes ao planejamento familiar e o álbum seriado "Planejamento familiar: direito sexual e reprodutivo" servirá como apoio. Já na $3^{\text {a }}$ etapa será salientado a importância do aleitamento materno exclusivo, orientações sobre a doação do leite materno, além do agendamento de uma consulta de puerpério pelo Agente Comunitário de Saúde para a Estratégia de Saúde da Família em questão. Será realizado também uma consulta de puerpério a cada participante pelos bolsistas do projeto. Neste ponto, será utilizado um álbum seriado confeccionado pelos bolsistas sobre o aleitamento materno exclusivo, denominado "Aleitamento Materno Exclusivo". Ressalta-se, que as gestantes que não se encontram no primeiro trimestre, também serão contempladas pelo projeto. Ainda, durante as VDs o cartão da gestante será checado pelos bolsistas, a fim de se verificar o correto preenchimento do mesmo, assim como haverá um caderno para anotações de identificação da participante. Com o desenvolvimento do projeto espera-se uma redução das gestações não planejadas durante a adolescência, assim como a promoção de uma gestação segura para o binômio materno-fetal, no município de Viçosa-MG. Dessa forma, por consequente, almeja-se uma redução nos índices de morbimortalidade relacionados à gestação na adolescência. A viabilização desse projeto contribuirá de forma significativa para a promoção da saúde e para a prevenção de doenças e agravos de gestantes adolescentes no município envolvido, assim como atuará como um método ativo em se formar profissionais críticos-reflexivos capazes de atuarem de acordo com a realidade em que estiverem inseridos.
\end{abstract}

Descritores: Saúde do adolescente; Gestantes; Promoção da saúde. 